\title{
The Effect of Using a Modified A/C System on the Cooling System Temperature of an Internal Combustion Engine
}

\author{
Mukhtar M.A. Morad ${ }^{* 1}$, Abdulwahab A. Alnaqi*1, Ahmad E. Murad ${ }^{* 1}$, Esam \\ A.M. Husain ${ }^{* 1}$, Hasan Mulla Ali ${ }^{* 1}$, Abdullah A.A.A. Al-Rashed ${ }^{* 1}$ \\ * Department of Automotive and Marine Engineering Technology, College of Technological Studies, The \\ Public Authority for Applied Education and Training, Kuwait
}

\begin{abstract}
This study investigates the effect of using A/C refrigerant to reduce the temperature of the coolant in a vehicle cooling system. An increase in coolant temperature due to harsh working conditions increases fuel consumption and leads to a reduction in engine power. Modifying vehicle air-conditioning by passing the suction line of the $\mathrm{A} / \mathrm{C}$ system through the heat exchanger located in the lower part of the radiator (down flow type) can significantly improve the performance of the engine cooling system. The results show a reduction in the temperature of coolant within the cooling system, thus maintaining a controlled working temperature within the allowable limits.
\end{abstract}

Keywords: A/C System, I.C.E, cooling system, performance

\section{INTRODUCTION}

The heat transfer within an IC engine is extremely important for proper engine operation. About $35 \%$ of the fuel energy that enters the engine is converted to useful crank shaft work, and about $30 \%$ of that energy is carried out from the engine in the exhaust flow in the form of enthalpy and chemical energy. The remaining one-third of the total energy is dissipated to the surroundings by some mode of heat transfer [1]. The behavior of an IC engine is more efficient when it is operating under normal thermal load. However, a rise in coolant engine temperature causes it to consume more fuel, and results in rough engine idling and less power propulsion [2-3]. A method is used in a refrigeration system, where a coolant-suction heat exchanger transfers energy from a warm coolant to a cool vapor at steady-state conditions to ensure proper system operation and increase in system performance. Improvements in performance using this method have prevented flash gas formation at inlets to expansion devices by ensuring evaporation of all liquid that may remain in the liquid suction prior to reaching the compressor. Such approach has been used to increase the efficiency of the refrigeration cycle [4], when the suction gas is super-heated by removing heat from the coolant. In the current study, the use of an A/C suction line was found to improve a vehicle cooling system. The aim of this study is to modify the A/C system in order to control the temperature of the vehicle coolant cooling system under harsh driving conditions where the ambient temperature reaches $55{ }^{\circ} \mathrm{C}$ in the shade during the summer season, as in Kuwait. This was accomplished by passing the relatively cold gas of the refrigerant leaving the evaporator (about $12.6{ }^{\circ} \mathrm{C}$ ) through the heat exchanger located in the lower part of the radiator (down flow type) instead of passing it to the inlet side of the compressor as in the conventional A/C system [5].

\section{THEORETICAL ANALYSIS}

\subsection{Energy distribution}

The amount of power available for use in an engine is shown as:

$$
\begin{aligned}
& P=\dot{m}_{f} Q_{H v} \\
& \text { Where: } \\
& P=\text { power } \\
& \dot{m}_{f}=\text { rate of fuel flow into the engine } \\
& Q_{H v}=\text { heating value of the fuel }
\end{aligned}
$$

The brake thermal efficiency gives the percentage of this total energy which is converted to useful output at the crank shaft, as shown:

$$
\eta_{t h}=\frac{P_{b}}{\dot{m}_{f} Q_{H v} \eta_{c}}
$$

Where:

$\eta_{t h}=$ thermal efficiency

$\eta_{c}=$ combustion efficiency

$P_{b}=$ brake power

The rest of the energy can be divided into heat losses, and losses in the exhaust flow [6].

For any engine, the power generation is equal to:

$$
P=P_{s}+Q_{a x}+Q_{L}+P_{a}
$$

Where: 
$P_{s}=$ brake output power of the crank shaft

$Q_{\theta x}=$ energy lost in the exhaust flow

$Q_{L}=$ all other energy lost to the surroundings

by heat transfer

$P_{a}=$ power to run engine accessories

For many engines, the heat losses can be subdivided as follows:

$$
\dot{Q}_{L}=\dot{Q}_{c}+\dot{Q}_{0}+\dot{Q}_{a}
$$

Where:

$\dot{Q}_{L}=$ all energy lost

$\dot{Q}_{c}=$ energy lost in the coolant $\simeq 10-30 \%$

$\dot{Q}_{0}=$ energy lost in engine oil $\simeq$ oil $5-15 \%$

$\dot{Q}_{a}=$ energy lost directly to the surroundings $\simeq 2$ $10 \%$

\subsection{Heat transfer in intake system}

The intake manifold is hot, either by design in some engines or just as a result of its location close to other hot components in the engine compartment. The walls of the intake manifold are hotter than the flowing gases. Heating of the walls by convection takes place according to the following equation:

$$
\begin{aligned}
& \dot{Q}=h A\left(T_{w}-T_{g}\right) \\
& \text { Where: } \\
& T_{w}=\text { temperature of manifold wall } \\
& T_{g}=\text { temperature of gas } \\
& h=\text { convection heat transfer coefficient } \\
& A=\text { inside surface area of intake manifold }
\end{aligned}
$$

\subsection{Heat transfer in combustion chamber}

Once the air-fuel mixture is in the cylinders of an engine, the three primary modes of heat transfer (conduction, convection and radiation) play an important role in smooth steady-state operation. During a combination of the three modes, peak gas temperatures in the order of $3000 \mathrm{~K}$ occur within the cylinder, and effective heat transfer is needed to keep the cylinder walls from overheating. Convection and conduction are the main heat transfer modes that remove energy from the combustion chamber and keep the cylinder walls from melting; accordingly, the heat transfer per unit surface area will be as follows:

$$
\dot{q}=\frac{\dot{Q}}{A}=\left(T_{g}-T_{c}\right) /\left[\left(1 / h_{g}\right)+(\Delta x / k)+\left(1 / h_{c}\right)\right]
$$

Where:

$T_{g}=$ gas temperature in the combustion chamber
$T_{c}=$ coolant temperature

$h_{g}=$ convection heat transfer coefficient on the gas side

$h_{c}=$ convection heat transfer coefficient on the coolant side

$\Delta x=$ thickness of the combustion chamber wall

$k=$ thermal conductivity of the cylinder wall

\subsection{Effect of engine operating variables on heat transfer}

Heat transfer within an engine depends on numerous variables and this makes it difficult to compare one engine with another. These variables are the air-fuel ratio, speed, load, brake mean effective pressure, spark timing, compression ratio, materials, and size. Temperature within an engine increases as engine speed increases, hence, heat transfer to the engine coolant increases with higher speed, as shown:

$$
Q=A h\left(T_{w}-T_{c}\right)
$$

Where:

$h$ = convection heat transfer coefficient, which remains constant

$A=$ surface area, which remains constant

$T_{c}=$ coolant temperature, which remains constant

$T_{w}=$ wall temperature, which increases with speed

Heat transfer within the engine also increases with increasing engine load, as shown:

$Q=h A j I . T$

Where:

$h=$ convection heat transfer

$A=$ surface area at any point

jI. $T=$ Temperature difference at that point

In internal combustion engines, the most popular and widely used method of cooling is the coolant that provides more uniform temperature around the combustion chamber than direct cooling by air. However, in this particular case the maximum temperature is limited by the properties of the coolant.

\subsection{Heat lost in engine}

The total quantity of heat generated in the engine and lost to the coolant is represented by:

$$
Q_{\text {engine }}=m c_{p} \Delta t
$$

Maintaining a constant cooling air mass flow through the engine, radiator, fan and vehicle is represented by:

$$
Q_{\text {engine }}=Q_{\text {radiator }}
$$




\subsection{Heat lost in radiator}

From energy conservation, the rate of heat dissipation from a radiator depends on the difference between the mean coolant temperature (average coolant temperature, $T_{f a v g}$ ) and the surrounding air temperature (ambient air temperature $T_{a}$ ).

The temperature drop across the radiator can be estimated by:

$$
T_{d}=\left[\frac{T_{f-\text { out }}+T_{f-i n}}{2}\right]-T_{a}
$$

Where:

$T_{d}=$ temperature drop

$T_{f \text {-out }}=$ outlet temperature

$T_{f-i n}=$ inlet temperature

$T_{\alpha}=$ ambient air temperature

Other considerations for effective heat dissipation are represented by the number of radiator tube rows and the arrangement of coolant velocity and air velocity. However, increasing coolant velocity leads to a waste of energy [7].

$$
V_{\alpha}=\frac{\text { Radiator inlet air flow }}{\text { surface area }}
$$

The air velocity is more important than the coolant velocity for effective heat dissipation. The purpose of the radiator is to transfer heat from the core fins to the ambient air temperature; air velocity depends on the vehicle speed, radiator size and cooling surface. The heat transfer area can be estimated from the relationship for the heat transmitted per unit time from a surface by convection, using:

$$
\begin{aligned}
& Q_{\text {radiator }}=A_{s} h_{c}\left(T_{f}-T_{s}\right) \\
& \text { Or } A_{s}=\frac{Q_{\text {radiator }}}{h_{e}\left(T_{f}-T_{s}\right)}
\end{aligned}
$$

Where:

$A_{s}=$ area of cooling surface

$h_{c}=$ convective heat transfer coefficient

$T_{s}=$ average wall surface temperature of radiator

$$
T_{f}=\text { mean coolant temperature between inlet }
$$
and outlet temperature

\subsection{Effective engine and coolant temperatures}

Suitable engine operation depends on certain safe working temperature ranges. Some factors can lead to reduced oil viscosity when operating at high coolant engine temperatures, causing loss of power. Furthermore, high temperatures can lead to top cylinder gasket damage. Also, when an engine operates at a high coolant temperature, this might cause the coolant to boil and evaporate, and in extreme cases causes loss of oil film. However, at low coolant engine temperatures, incomplete combustion may occur, leading to excessive fuel consumptions for proper engine performance. Moreover, the maximum possible coolant temperature is limited by the coolant boiling point and the radiator's heat transfer capacity. This depends on the number of fins, radiator surface area and thickness, and the number of coolant tubes.

\subsection{Heat transfer coefficient}

During the combustion process, the heat is transferred from the combustion gases to the combustion chamber wall, where the overall heat transfer coefficient $h$, is the sum of a convection heat transfer coefficient, $h_{c}$, and radiation heat transfer, hr [8].

$$
\begin{aligned}
& \text { Where: } \\
& h=h_{c+} h_{r}
\end{aligned}
$$

\subsection{Cooling area consideration}

The number of radiator tubes can be estimated from the mass flow rate of circulating coolant as shown:

$$
m=A_{t} v_{p}\left[\left(\frac{\pi d^{2}}{4}\right) n\right] v_{p}
$$

$\therefore$ The number of tubes $n$ is equal to:

$$
n=\frac{4 m}{\pi d^{2} v_{p}}
$$

\subsection{Properties of the coolant}

The physical properties of the coolant are the density, specific heat at constant pressure and the viscosity. Coolant density varies as a function of temperature; in addition, the specific heat of coolant at constant pressure $c_{p}$ is also affected by changes in engine temperature.

\subsection{Engine thermal efficiency}

The engine thermal efficiency varies from $25-35 \%$ for gasoline engines. This efficiency is an indication of the amount of useful work produced compared to the total supplied fuel energy and is given by the following equation:

$$
\begin{aligned}
& \eta_{\text {th }}=\frac{\text { Engine output energy }}{\text { Engine input energy }} \\
& =\frac{Q_{\text {out }}}{Q_{\text {in }}}
\end{aligned}
$$


Heat lost $\mathrm{x}$ quantity of heat supplied = quantity of heat dissipated $=$ quantity of heat supplied $=$ engine energy input $=$ quantity of heat dissipated $\mathrm{x}$ heat lost [9].

In the current study the $\mathrm{A} / \mathrm{C}$ system was utilized in order to control the coolant engine temperature. This was accomplished by using a real vehicle which has all the necessary mentioned components. The concept of the modified cooling system was to use the low pressure, or the suction, side of the refrigerant (containing the relatively cold gas) leaving the evaporator on its way to the compressor, and to pass it to the heat exchanger installed in the lower part of the radiator (down flow radiator). The heat transfer principle in the heat exchanger is based on a cold gas gaining heat from a hotter coolant. The theoretical heat transfer of a coolant is represented by the following formula [10]:

$$
Q_{t}=m c_{p} \Delta T \text { (theoretical) }
$$

Where:

$Q_{t}=$ total heat load

$m$ = mass flow rate of coolant

$C_{p}=$ specific heat of coolant at a constant pressure

\section{$\Delta T=$ change of temperature of coolant}

The practical heat transfer is a function of the physical geometry of the heat exchanger. The general form of the equation defining the maximum potential heat transfer through the heat exchanger is presented by the following formula:

$$
Q_{p}=U . A . \Delta T_{L . H}
$$

Where:

$Q_{p}=$ total heat load (practical)

$U=$ overall heat transfer coefficient

$A=$ surface area

$\Delta T_{L . H}=$ logarithmic mean temperature difference

$\Delta T_{L . H}=\frac{\Delta T_{1}-\Delta T_{2}}{\operatorname{Ln}\left(\frac{\Delta T_{1}}{\Delta T_{2}}\right)}$

$\Delta T_{1}=T_{h i}-T_{c o}$

$\Delta T_{2}=T_{h o}-T_{c i}$

Where:

$T_{h i}=$ inlet temperature of hot coolant

$T_{c o}=$ outlet temperature of cold coolant
$T_{\text {ho }}=$ outlet temperature of hot coolant

$T_{c i}=$ inlet temperature of cold coolant

While the hot coolant continues to move in the lower part of the radiator, the heat will be transferred to the other tube which is filled with cold fluid (A/C refrigerant) until the heat of the coolant is reduced. Implementing an $\mathrm{A} / \mathrm{C}$ suction line in the current study was found to improve the performance of a vehicle cooling system. This approach has been proven to increase the efficiency of the refrigeration cycle [4] when the suction gas is super-heated by removing heat from the coolant [11].

The idea was to pass the refrigerant gas in the suction side of the $\mathrm{A} / \mathrm{C}$ system of a vehicle directly to the heat exchanger instead of passing it to the compressor as shown in Figure 1. This can be controlled by a solenoid switch located between the evaporator and the compressor to adjust the flow of refrigerant either directly to the compressor or to the lower part of the heat exchanger in the radiator (down flow radiator). The inlet temperature of the $\mathrm{A} / \mathrm{C}$ gas entering the exchanger is around $\left(12.5 C^{\circ}\right)$, and as it leaves is around $\left(29 C^{\circ}\right)$. The current study investigates the performance of an R134 an vehicle air conditioning system [12]. The coolant temperature in the upper part of the radiator is around $\left(95 C^{\circ}\right)$, and it leaves the lower part of the radiator at around $\left(89 \mathrm{C}^{\circ}\right)$. The amount of heat lost by the radiator is equal to:

$$
Q_{r}=m c p \Delta T
$$

In addition, the heat lost by the refrigerant in the heat exchanger is given by:

$$
Q_{c}=m c p \Delta T
$$

Where:

$Q_{r}=$ the quantity of heat lost by the refrigerant in the heat exchanger

$Q_{c}=$ the quantity of heat lost by the coolant in the radiator

Assuming a constant cooling air passing through the engine radiator and $\mathrm{A} / \mathrm{C}$ condenser, then $Q_{r}=Q_{c}$

The following empirical formula was used to compute the outlet temperature of the suction line heat exchanger leaving the radiator [13]:

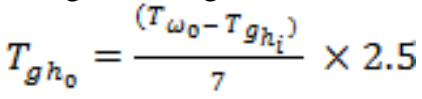

Where:

$T_{g h_{0}}=$ outlet gas temperature from heat exchanger

$T_{\omega_{0}}=$ outlet coolant temperature at lower part of radiator

$T_{g_{h_{\tilde{i}}}}=$ inlet gas temperature to heat exchanger 


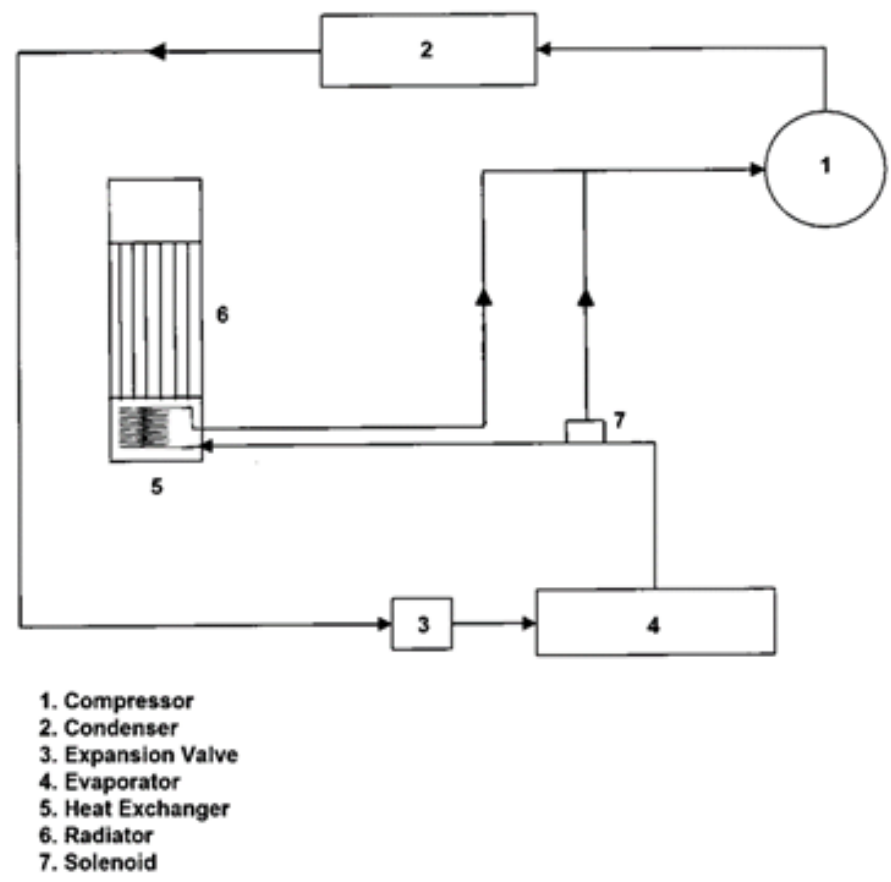

Figure 1: Proposed modified A/C system

Table 1: Summary of recorded A/C system temperatures $\left({ }^{\circ} \mathrm{C}\right)$, July $20^{\text {th }}$-Aug $10^{\text {th }} 2016$

\begin{tabular}{|c|l|c|c|c|c|c|c|c|c|c|}
\hline \multirow{2}{*}{ No } & \multicolumn{2}{|c|}{ TIME } & $11: 00$ & $11: 30$ & $12: 00$ & $12: 30$ & $1: 00$ & $1: 30$ & $2: 00$ \\
\cline { 2 - 9 } & \multicolumn{1}{|c|}{ TEMPERATURE PARAMETERS } & \multicolumn{7}{|c|}{ TEMPERATURES } \\
\hline 1 & T gas out of compressor (Tgc) & 93 & 95 & 95 & 96 & 96 & 96 & 95 \\
\hline 2 & T gas inlet to condenser (Tgi) & 92 & 93 & 93 & 94 & 95 & 95 & 94 \\
\hline 3 & T gas outlet from condenser (Tcg) & 90 & 91 & 91 & 92 & 93 & 92 & 92 \\
\hline 4 & T gas outlet from evaporator (Teg) & 12.6 & 12.4 & 12.7 & 12.8 & 12.5 & 12.4 & 12.4 \\
\hline 5 & T gas inlet to heat exchanger (Tghi) & 13 & 12.8 & 13.1 & 12.8 & 13.2 & 13.3 & 13.1 \\
\hline 6 & T gas outlet from heat exchanger (Tgho) & 29 & 29.2 & 28.9 & 29.3 & 32.8 & 30.7 & 33.9 \\
\hline 7 & T ambient outdoor (To) & 44 & 46 & 48 & 48 & 50 & 51 & 50 \\
\hline
\end{tabular}

III. EXPERIMENTAL PROCEDURE

\subsection{Experimental Apparatus}

A conventional Toyota Corolla 2011, 1.8L vehicle equipped with an air conditioning system consisting of a compressor, condenser, expansion valve and evaporator was used. The tests were conducted under high thermal load (high ambient temperature) with the $\mathrm{A} / \mathrm{C}$ engaged during the entire test period. The temperature of the cooling system coolant was recorded during an urban driving cycle for both upper and lower radiator tanks (down flow radiator). The results showed significant differences between the two readings, as described in detail in ref [14].

\subsubsection{Conventional system}

Figure 2 shows a typical configuration for the automotive air conditioning system installed in an automotive passenger car. The vehicle was driven under harsh conditions where the ambient temperature reached $\left(55^{\circ} \mathrm{C}\right)$ in the shade between $11 \mathrm{am}$ and $2 \mathrm{pm}$. This is typical of the summer months of July to August in Kuwait. The tests were conducted at different road locations and with traffic congestion. The temperatures were recorded at various points in the vehicle such as the radiator, compressor (high pressure and low pressure), and both inlets and outlets of the condenser and evaporator. Table (1) shows the recorded temperatures. 


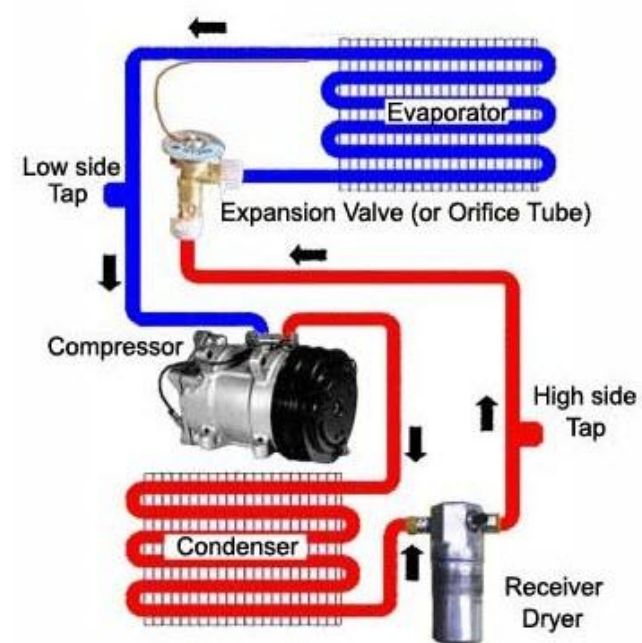

Figure 2: The conventional A/C System
Figure 3 shows the modified automotive air conditioning system with a solenoid device interposed between the evaporator and the compressor to control the flow of low pressure refrigerant (suction line) either directly to the compressor or to the heat exchanger. The purpose of the modified system is to reduce the engine coolant temperature by using the heat exchanger located in the lower part of the radiator (down flow type), where coolant temperature is relatively low, due to the heat lost through the radiator. Coolant temperatures were recorded at different points for different modes of driving, including low speed and in congested traffic. The results are shown in Table 2 .

\subsubsection{Modified system}

Table 2: Recorded temperatures for the engine cooling system

\begin{tabular}{|c|l|c|c|c|c|c|c|c|c|c|}
\hline \multirow{2}{*}{ No TIME } & \multicolumn{1}{|c|}{$11: 00$} & $11: 30$ & $12: 00$ & $12: 30$ & $1: 00$ & $1: 30$ & $2: 00$ \\
\cline { 2 - 10 } & TEMPERATURE PARAMETERS & \multicolumn{7}{|c|}{ TEMPERATURES } \\
\hline 1 & T coolant inlet to radiator (Twi) & 90 & 93 & 96 & 99 & 102 & 101 & 103 \\
\hline 2 & T coolant out of radiator (Two) & 86 & 88 & 90 & 92 & 96 & 95 & 97 \\
\hline 3 & T Ambient outdoor (To) & 44 & 46 & 48 & 48 & 50 & 51 & 50 \\
\hline 4 & T Ambient cabin (Tc) & 28 & 31 & 32 & 34 & 33 & 32 & 31 \\
\hline 5 & T Ambient under hood (Th) & 84 & 87 & 88 & 91 & 93 & 93 & 92 \\
\hline 6 & T coolant out of radiator (TWD) (modified) & 82 & 85 & 87 & 89 & 91 & 90 & 91 \\
\hline
\end{tabular}

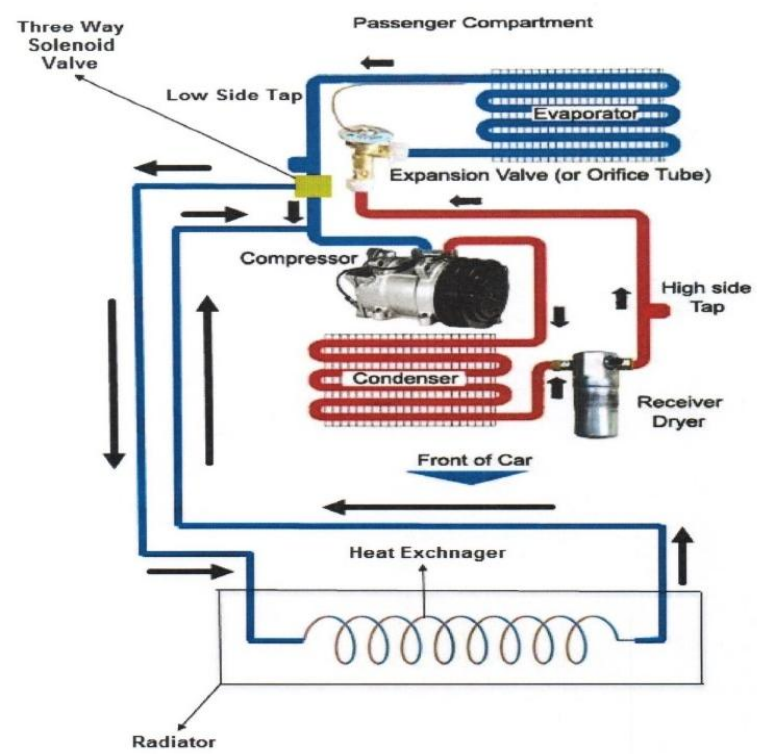

Figure 3: The modified A/C system

\subsection{Experimental conditions}

The system was tested on a real automotive vehicle under harsh conditions with the $\mathrm{A} / \mathrm{C}$ switched ON for the entire test' procedure. The recorded temperatures are summarized in Tables 1 and 2. The temperature outside the compressor/condenser reached steady-state during normal operation and the temperature of the air blowing out of the condenser unit was subjectively judged to be warmer than that of the ambient air'. This was due to the better heat transfer from the compressed refrigerant which was about $92^{\circ} \mathrm{C}$ inside the condenser coil, to the outside air where the ambient temperature was about $65^{\circ} \mathrm{C}$. As a result of this, the refrigerant temperature was reduced to $90^{\circ} \mathrm{C}$. Thus, the temperature of the air was reduced as it moved across the evaporator coil where the outlet temperature of the refrigerant was $12.6^{\circ} \mathrm{C}$. This working temperature of the liquid gas remains low as it drains into the compressor (conventional type). However, in the modified system, the suction outlet containing the liquid refrigerant drains into the 
heat exchanger unit (installed in the lower part of the radiator of the vehicle (down flow type) which is in contact with the warmer coolant of the cooling system. As a result, the cooling system performance is improved when the coolant loses heat while moving around the modified heat exchanger, as shown in Figure 3, thus lowering the outlet coolant temperature entering the engine.

\section{RESULTS AND DISCUSSION}

The present study shows experimental results for both the conventional and the modified systems. The experimental results indicate an increase in the temperature of the gas leaving the modified heat exchanger, as shown in Figure 4. This is a result of the cold refrigerant losing its temperature after passing through the heat exchanger which contains the hot coolant of the cooling system. While the temperature of the refrigerant gas was almost steady in the conventional system, this was not the case with the modified system, where the results showed an increase in refrigerant temperature after $1 \mathrm{pm}$. This approach improved the performance of the cooling system by reducing the coolant temperature of the lower tank of the radiator entering the cylinder block of the engine, as shown in Figure 5. This improvement in lowering the temperature of the coolant was noticed clearly after $1 \mathrm{pm}$ when the vehicle was driven under harsh conditions and in high ambient air temperatures of above $\left(55^{\circ} \mathrm{C}\right)$ specifically during the summer months of July to August in Kuwait. Implementation of the modified system is thus proven to help overcome the overheating problem, especially in extreme weather conditions such as those experienced in Kuwait between July and August.

The results of the study show a reduction in the potential for overheating and consequent gasket damage, and hence an improvement in engine performance when using the modified system in all driving modes, including low engine speed, high engine speed and traffic congestion.

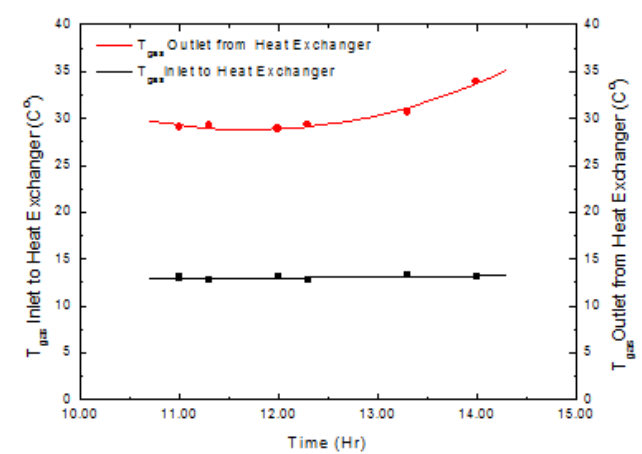

Figure 4: Comparison between inlet and outlet refrigerant gas temperatures using the modified $\mathrm{A} / \mathrm{C}$ system

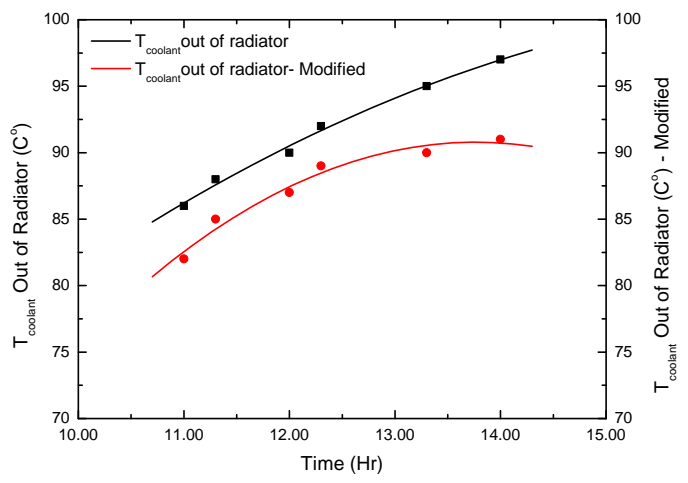

Figure 5: Comparison between coolant temperatures of conventional and modified $\mathrm{A} / \mathrm{C}$ systems

\section{CONCLUSION}

A modified air-conditioning system was tested in the current study. From the theoretical study analysis, better control of engine working temperature was accomplished by passing the relatively cold gas of the refrigerant leaving the evaporator (about $12.6{ }^{0} \mathrm{C}$ ) through the heat exchanger located in the lower part of the radiator (down flow type) instead of passing it to the inlet side of the compressor as in the conventional $\mathrm{A} / \mathrm{C}$ system.

This method was proven to absorb heat from the coolant in the cooling system of the vehicle during different modes of operation and under harsh Kuwaiti conditions, specifically in summer. The theoretical calculations and analysis show a temperature drop when using the modified $\mathrm{A} / \mathrm{C}$ system as a means of controlling engine operating temperature under high thermal load. This study will influence the management of engine working conditions in Kuwait to maintain normal engine operating temperatures, especially in traffic and during rush hours.

It can be concluded from this study that the use of a modified automotive air conditioning system was very useful at high ambient air temperatures. It improved the performance of an automotive cooling system during all modes of vehicle operation and under harsh conditions in Kuwait, where the working temperatures were high in the summer months of July and August.

It was concluded from this analysis that, when using the modified system, the temperature of the liquid refrigerant increases, leading to an improvement in the performance of the A/C system. For this reason, it is suggested that further studies can be carried out on the $\mathrm{A} / \mathrm{C}$ modified system used in this study, with the same high ambient temperature in summer season in Kuwait. 


\section{REFERENCES}

[1]. M. Morad, J. Alrajhi, "The Effect of High Temperature on Engine Performance in Kuwait Conditions", Journal of Mechanical Engineering and Automation, Volume 4(2): pp. 55-62, 2014.

[2]. Abdul Aziz, Mohamad Fuad (2015) The effect of ambient temperature to the performance of internal combustion engine. Master's thesis, Universiti Tun Hussein Onn Malaysia.

[3]. Effect of ambient temperature and humidity on combustion and emission of spark assisted compression ignition engine, conference paper, November 2015 ASME, International combustion engine.

[4]. 2006 ASHRAE Handbook - Refrigeration (I$P$ Edition). American Society of Heating, Refrigerating and Air-Conditioning Engineers, Inc. Online version available at: http://app.knovel.com/hotlink/toc/id:kpASHR AEH1/ashrae-handbook-refrigeration/ashraehandbook-refrigeration

[5]. Domanski, P.A., Didion D.A. and Doyle J.P., Evaluation of suction line heat exchanger in the refrigeration cycle, Int. Volume 17, No. 7, pp. 487-493 (1994).

[6]. Rakopoulos, C.D. and C.N. Michos. "Development and validation of a multi-zone combustion model for performance and nitric oxide formation in syngas fueled spark ignition engine." Energy Conversion and management 49.10 (2008): 2924-2938.

[7]. Rakopoulos, C.D. and E.G. Giakoumis. "Second-law analyses applied to internal combustion engines operation." Progress in Energy and Combustion Science 32.1 (2006): 2-47.

[8]. Preissner, Marcus, Brett Cutler, R. Radermacher, and C.A. Zhang. "Suction line heat exchanger for R134a automotive airconditioning system", International Refrigeration and Air Conditioning Conference (2000).

[9]. S.A. Klein, D.T. Reindle, and K. Brownell, "Refrigeration System Performance using Liquid - Suction Heat Exchangers", International Journal of Refrigeration, Vol. 23, Part 8, pp. 588-596.

[10]. Technical Exchange, Suction Line Heat Exchanger 2010, Doicette Industries Inc, 20 Leigh Drive, York, Pennsylvania 17406-8474.

[11]. J. Steven Brown, F. Samuel, Yana-Matta, Piotr A. Domanaski, "Comparative Analysis of an Automotive Air Conditioning Systems Operating with $\mathrm{CO}_{2}$ and R134a", Catholic University of America, Washington D.C USA, Formerly NIST., Presently Honeywell International Inc. Buffalo, NY, USA.
[12]. P.A. Domanski, D.A. Didion, J.P. Doyle, "Evaluation of Suction Line - Liquid Line Heat Exchanger in the Refrigeration Cycle", International Journal of Refrigeration, $\mathrm{pp}$. 487-493, 1994.

[13]. Y.C. Park, R. Mc Enaney, D. Boewe, J.M. Yin, P.S. Hrnjak, "Steady State and Cycling Performance of a Typical R134a Mobile A/C System", SAE International Congress and Exposition Detroit, Michigan, paper no. 199901-1190, 1999.

[14]. Brace, C.T., Hawley. J.G, Akekwrst, S., Piddock, M. and Peg. I. (2008), Cooling system improvements - Assessing the effects on fuel economy and engine performance. 